Boise State University

ScholarWorks

Criminal Justice Faculty Publications and

Presentations

Department of Criminal Justice

$1-1-2011$

\title{
Disentangling the Relationship Between Child Maltreatment and Violent Delinquency: Using a Nationally Representative Sample
}

Ilhong Yun

Boise State University

Jeremy D. Ball

Boise State University

Hyeyoung Lim

Western Illinois University 


\title{
Disentangling the Relationship Between Child Maltreatment and Violent Delinquency: Using a Nationally Representative Sample
}

\author{
Ilhong Yun \\ Boise State University \\ Jeremy D. Ball \\ Boise State University \\ Hyeyoung Lim \\ Western Illinois University
}

\begin{abstract}
This study uses the National Longitudinal Study of Adolescents (Add Health) data, a nationally representative sample of adolescents, to disentangle the relationship between child maltreatment and violent delinquency. Also examined are potential moderating effects of gender, socioeconomic status (SES), and religiosity on the association between child maltreatment and violent delinquency. Contrary to prior research findings, the current analyses reveal that physical abuse is not associated with future violent delinquency, whereas sexual abuse and neglect predict violent delinquency significantly. The current study also did not reveal any moderating effects of gender, SES, and religiosity on the association between maltreatment and violent delinquency. Interpretations of these findings are presented, drawing on the properties of the national probability sample compared to the findings of most prior studies that used localized samples.
\end{abstract}

Every year, nearly 1,000,000 children in the United States are abused and/or neglected (U.S. Department of Health and Human Services, 2006). Research on the impact of child abuse and neglect consistently highlights the deleterious effects of such maltreatment. A wealth of empirical evidence demonstrates that children who are either abused or neglected exhibit problems in multiple dimensions including later involvement in violent delinquency and crime (Cicchetti \& Barnett, 1991; Dodge, Pettit, \& Bates, 1997; English, 1998; Kim, 2008).

The link between child maltreatment and violent delinquency has particularly garnered a sizable interest from many empirical researchers in recent decades. A number of methodologically robust longitudinal studies have supported the hypothesis that violent delinquency is a result of child maltreatment (English, Widom, \& Brandford, 2002; Widom 1989a, 1989b, 1989c). In their comprehensive review of the maltreatment literature to date, Maas, Herrenkohl, and Sousa (2008) recently concluded that physical abuse of a child is the most consistent type of abuse predicting youth violence.

Despite the widely accepted association, however, much of the research has focused on the relationship between physical abuse and later violence, primarily guided by the "violence begets violence" or "cycle of violence" framework; in contrast, attention to other forms of abuse, such as neglect, has been relatively low. But such sole focus on physical abuse is not a particularly promising approach because the vast majority of child maltreatment incidents involve some form of neglect (Mersky \& Reynolds, 2007; Widom, 1989a; 1989c). Evidence is also emerging that neglect is related to delinquency (Smith \& Thornberry, 1995; Widom 1989c; Zingraff, Leiter, Myers, \& Johnsen, 1993).

Research findings that support the cycle of violence thesis are primarily based on local samples derived from disadvantaged backgrounds or samples that have undergone the more serious forms of maltreatment, frequently substantiated by child protective agencies. For instance, study samples were drawn from child welfare and protective service agencies (Herrenkohl, Egolf, \& Herrenkohl, 1997), youths in high crime areas (Smith \& Thornberry, 1995), low income communities (Farrington, 1989), and otherwise at-risk youths (Loeber et al., 2005). In contrast, tests of the cycle of violence thesis with a nationally representative sample, not based on maltreatment or delinquency status, are relatively few. Thus, there is relatively little known about the impact of less serious maltreatment on violent delinquency. Although much understanding has been gained with respects to child maltreatment occurring in 
disadvantaged settings as a more extreme form of abuse and neglect, knowledge of negative effects of child maltreatment can also be obtained by studying nationally representative samples of children and adolescent population.

Furthermore, most previous studies did not exclusively isolate violent offenders from offenders who engage in both violent and property delinquency. As such, estimates could have been confounded due to the fact that the majority of violent offenders also perpetrate property offenses. In the current study, the effect of maltreatment on exclusive participation in violent delinquency is examined.

It appears that maltreated children, in general, share a higher likelihood of getting involved in violent delinquency than non-maltreated children. The puzzling question is why a greater portion of maltreated children do not turn out to be violent delinquents. In fact, many abused and neglected children grow up to become law-abiding and constructive citizens. In contrast, children who have not been subject to maltreatment are noted to take the path of delinquency and crime. This phenomenon suggests a complex interaction among maltreatment, delinquency, and moderating factors between them. Yet, relatively few studies have delved into the interactions of other conditions or resilient factors with maltreatment and how such variables modify the impact of maltreatment on delinquency. In this study, using a nationally representative sample of adolescents, we examine the effects of self-reported child maltreatment on violent delinquency. Additionally, we examine the effects of interactions between maltreatment and three variables - gender, SES, and religiosity — on violent delinquency.

\section{Gender, Maltreatment, and Delinquency}

One of the most robust findings in the juvenile delinquency literature is that males commit more delinquency than females. Thus, investigation of the etiology of delinquency has traditionally focused on the etiology of male delinquency (e.g., Hirschi, 1969). Yet, during the recent decades, an increasing involvement of females in delinquency and crime has been observed across most offense types (Snyder \& Sickmund, 2006), accompanied by a fast growth of incarcerated female population. Concomitantly, an increasing number of researchers have set out to investigate potential risk factors that might operate differentially between males and females.

Recent evidence suggests a possible gender difference in the effect of childhood neglect and abuse on the risk of delinquency. Contrary to earlier beliefs, maltreated females during childhood seem to be at an equal or higher risk of delinquency than maltreated males (English et al., 2002; Widom \& Maxfield, 2001). For instance, Widom \& Maxfield (2001) report maltreated females were 73\% more likely than non-maltreated females to be arrested, while a similarly distinctive contrast was not observed among the male sample. Most studies that examine the effect of gender in the relationship between child maltreatment in criminality use local samples. The current study employs an interaction term of maltreatment and gender to examine whether such findings in previous studies hold true given a nationally representative sample of adolescents.

\section{SES, Maltreatment, and Delinquency}

It has been found that children from disadvantaged families are more likely to engage in delinquent behaviors. At the same time, children from disadvantaged families are more likely to be neglected and abused (English, 1998; Mersky \& Reynolds, 2007). Thus, it is customary that researchers investigating child maltreatment control for the effects of SES. But very few researchers have examined the joint effects of maltreatment and SES on delinquency. One study that did examine the interaction effect is based on a sample consisting of a cohort of disadvantaged minorities in the Chicago area (Mersky \& Reynolds, 2007). In their study, Mersky and Reynolds (2007) did not observe any moderating effects of SES on the relationship between maltreatment and delinquency.

\section{Religiosity, Maltreatment, and Delinquency}

The existing resilience literature suggests that religiosity is protective against a host of adolescent risk behaviors, including violent delinquency. The consensus is that religiosity moderates the effect of various life-strain and helps individuals cope in a positive way. Higher levels of religious commitment have been associated with lower alcohol use (Cochran \& Akers, 1989; Miller, Davies, \& Greenwald, 2000), cigarette use (Wallace \& Forman, 1998), marijuana use (Miller et al., 2000; Wallace \& Forman, 1998), and illicit drug use (Amey, Albrecth, \& Miller, 1996; Miller et al., 2000). In addition, studies specifically targeting disadvantaged groups also show positive effects of 
religiosity. For instance, in a longitudinal study of inner-city high-risk children, Werner and Smith (1982) found that spirituality was one of the most salient protective factors that rendered the children to fare well academically. In a similar vein, using the National Longitudinal Study of Adolescents (Add Health) data, Regnerus and Elder (2003) found that religiosity was the key resilient factor that helped disadvantaged children to stay on track in school. Thus, it seems that religiosity, despite negative life experiences and accompanying strain, provides individuals with a sense of purpose and coping resources on which they can draw.

Early studies construed religiosity as a unidimensional construct and primarily used church attendance as the sole measure of religiosity (Johnson, Marcos, \& Bahr, 1987; Tittle \& Welch, 1983). More recent studies, however, tend to acknowledge the multidimensionality of the religiosity construct. Furthermore, empirical results appear to depend on whether the multidimensionality of religiosity is taken into account or not. For instance, Johnson, De Li, Larson, and McCullough's (2000) review showed that studies were more likely to yield beneficial effects of religiosity when multiple dimensions of religiosity were examined, as compared to when only a single dimension was examined.

Given the review of the literature, one might surmise that child maltreatment is positively associated with delinquency while religiosity reduces delinquency through its buffering effects. Surprisingly, however, no known studies have examined the moderating effects of religiosity in the nexus of maltreatment and delinquency. The current study sets out to investigate this relationship based on a hypothesis that religiosity moderates the negative effects of maltreatment, thereby lowering the likelihood of violent delinquency among maltreated children.

In short, the current study closely investigates the effects of child maltreatment on future involvement in violent delinquency using a national probability sample of adolescents. The overarching hypotheses of this study are that any form of child maltreatment at the hands of parents or care-givers increases the child's later engagement in violent delinquency, and that this relationship is moderated by gender, SES, and religiosity.

\section{Methodology}

\section{Data}

The sample for this study was extracted from the public-use data of the National Longitudinal Study on Adolescent Health ("Add Health" hereafter) (Bearman, Jones, \& Udry, 1997). Known as the largest, most comprehensive longitudinal survey of nationally representative sample of adolescents ever undertaken, the first wave of Add Health data was collected in 1994-1995 from adolescents in grades 7 through 12 . With a relatively low attrition rate, wave II data were collected in 1996, while Wave III data were collected in 2001-2002, when the initial participating adolescents reached the young adult stage.

The Add Health collects childhood maltreatment information retrospectively at Wave III when participants reached young adulthood $(\mathrm{N}=4,882)$. Important information on adolescents' involvement in delinquency behavior was garnered from the data during Wave II. Information on gender, household income, and childhood religiosity were collected from Wave I data. Thus, the study sample is restricted to the cases that contain sufficient information on the research variables across the three waves of data collection. The data are further restricted by eliminating cases with missing values on any of the violent delinquency indicators and maltreatment indicators. After cases with such missing values were eliminated, the final sample consisted of 3,472 cases. Among them, females constitute 53.9\% and males 46.1\%. Since Add Health's sampling design involves an oversampling of certain minority groups, Black respondents' representation $(22.7 \%)$ is higher than their representation in the general population, while Hispanics constitute $10.9 \%$ of the sample.

\section{Outcome Variables}

Outcome variables for violent delinquency are measured using seven items associated with self-reported violent acts. Respondents were asked how often they participated in the following acts during the 12 months preceding the interview: used or threatened to use a knife or gun to get something from someone; took part in a gang fight; pulled a knife or gun on someone; shot or stabbed somebody; got in a serious physical fight; used a weapon in a fight; hurt someone badly. Respondents were to choose an option from never (1), one or two times (2), three or four times (3), or five or more times (4). In order to disentangle the effect of maltreatment on violent delinquency, we constructed the following three outcome variables. 
Violence participation. A dichotomous variable was constructed, coding individuals with at least one reported violent offending as 1 and individuals without such reporting as 0 .

Violence frequency. Although useful, participation, per se, cannot discriminate serious and habitual offenders from less serious one- or two-time offenders. Thus, the frequency of violent offending constitutes an additional outcome variable. For this purpose, a count variable was constructed by summing the frequency scores across the seven violent delinquency items (Cronbach's alpha=.84).

Exclusive violence participation. In order to address the concern that estimates could be confounded by the fact that the majority of adolescents who committed violent offending also engage in property offending (53\% in the current sample), a third outcome variable, exclusive violence participation, is constructed. For this variable, any individual who reported violent offending, but who did not report any property offending, is coded 1.

Regarding those who reported both violent and property offending ("dual offenders"), two different regression techniques were utilized. First, multinomial logistic regression models were estimated, comparing exclusively violent offenders (1), exclusively property offenders (2), and dual offenders (3) to a reference group of nonoffenders (0). Second, probit regression models were estimated by excluding these dual offenders from the analyses altogether. ${ }^{1}$ Non-offenders are coded as 0 . For ease of presentation, we only present the results of the probit regression analyses; the results of the multinomial logistic regression analyses are presented in the Appendices.

\section{Predictors}

Childhood maltreatment was measured by using retrospective accounts, collected at wave III, of maltreatment occurring before entrance into sixth grade. Specifically, they were asked how often their parents or other adult caregivers: (physical abuse) slapped them or hit/kicked them; (sexual abuse) touched them in a sexual way, forced them to touch him/her in a sexual way, or forced them to have sexual relations; (neglect) left them home alone when an adult should have been with them or had not taken care of their basic needs, such as keeping them clean or providing food or clothing. Answer categories provided were one time (1), two times (2), three to five times (3), six to ten times (4), and more than ten times (5). Some child maltreatment researchers recommended specifying the taxonomic categories, instead of using an aggregated indicator, of multiple types of maltreatment (Cicchetti \& Barnett, 1991; Mersky \& Reynolds, 2007; Zuravin, 1999). Therefore, multiple indicators of maltreatment were created.

Physical abuse. A dichotomous measure of physical abuse was created based on the answers to the question of how many times parents or adult caregivers had slapped them or hit/kicked them. Considering the possibility that physical punishment could occur in the form of hitting or slapping even in non-abusive families, only the respondents who reported three or more times physical abuse were coded 1 , and all others 0 .

Sexual abuse. A dichotomous measure aggregates reported times of sexual abuse. Unlike physical abuse, respondents reporting any type of abuse were coded 1 , while 0 was given to those who did not report any sexual abuse incidents.

Neglect. A dichotomous measure of neglect reflects whether the respondent was left home alone or was not taken care of basic needs. Considering the relatively frequent occurrences of such incidents even in non-abusive homes$39 \%$ of our sample reported having been subject to either form of neglect at least once-only those who reported more than ten times of such neglect were coded $1(8.93 \%)$, and all others 0 .

Any Maltreatment. To capture the overall impact of maltreatment on delinquency, an aggregate measure of maltreatment was also created. Respondents whose value is 1 for any of the above-mentioned three specific indicators of maltreatment were coded 1, otherwise 0 .

\footnotetext{
${ }^{1}$ Originally we aggregated these "dual" offenders and non-offenders together, coding them as 0 , and ran negative binomial regression models. All of the resulting negative binomial regressions produced a null finding. In light of one of the anonymous reviewers' suggestion that the null findings may have been resulted from aggregating the dual offenders and non-offenders, these two different regression techniques were ran to make assurances.
} 
Substantiated maltreatment. Retrospective self-reports of childhood maltreatment can be subjective and hold the potential of having reduced validity. For instance, adolescents and adults who engage in crime and delinquency tend to exaggerate their maltreatment experiences as a child to rationalize their current deviant behaviors (Cicchetti \& Toth, 1993). Thus, a conservative measure of maltreatment, termed substantiated maltreatment, was also employed, denoting that the respondent had actually been taken out of home by Social Services due to maltreatment. Substantiated maltreatment is also a dichotomous variable with the value of 1 for those who had been taken out of home at least once by Social Services by the time they started sixth grade and 0 for those who had not.

\section{Moderating Variables}

Three variables are examined as potential moderators of the link between maltreatment and delinquency. Female is a binary variable (male $=0$, female $=1$ ), and Household income was measured through the interview of parents during Wave I. It is a continuous variable ranging from \$0 to \$999 thousand dollars.

Taking recent scholars' emphasis on the multidimensionality of religiosity, we measure two different dimensions of religiosity - public domain and private domain. Public religiosity was the mean response to two questions about the past twelve months: "How often did you attend religious services?', and "Many churches, synagogues, and other places of worship have special activities for teens - such as youth groups, Bible classes, or choir. How often did you attend such religious activities?" Responses range from once a week or more (4) to never (1). Private religiosity was the mean response to two questions: "How important is religion to you?" and "How often do you pray?" Responses to the first question range from very important (4) to not important at all (1). Responses to the second question range from at least once a day (5) to never (1). Both religiosity variables were recoded in a way that higher scores represent higher religiosity.

In the main effects models, these moderators were treated as covariates. ${ }^{2}$ For interaction models, interaction terms are created as a multiplicative function between each moderator and the variable "Any Maltreatment." Each interaction term was centered by subtracting the sample mean of each main effect variable from the interaction term components, thereby reducing multicollinearity between the main effect variables and the interaction terms (Aiken \& West, 1991).

\section{Analytic Strategy}

For the dichotomous outcomes - Violence Participation and Exclusive Violence Participation - multivariate probit regressions are performed. Probit models are guided by similar assumptions and estimation techniques as logistic regression and their results are only minimally different (Long \& Freese, 2006). Probit models use, however, the inverse of the standard normal cumulative distribution instead of the log function used in logistic regression.

For the count outcome variable, Violence frequency, a highly positively skewed distribution was found, which traditional OLS is not suited to handle. In such a case, Poisson-based regression models are a better option because they precisely take into account the discrete, highly skewed nature of the count dependent variables (Osgood, 2000). Because the count variables also exhibited an over-dispersion ${ }^{3}$, i.e. variance much larger than the mean, negative binomial regression is employed. Negative binomial regression is a Poisson-based model that relaxes the equidispersion assumption of Poisson regression, thereby proving the most widely used technique for over-dispersed count data (Gourieroux, Monfort, \& Trognon, 1984).

The National Longitudinal Study of Adolescent Health is a high school-based multistage, cluster sampling design study. Thus, individuals' error terms might not be independent of each other due to clustering in the same school, thereby leading to deflation of estimated standard errors (Byrk \& Raudenbush, 1992). To account for this problem of heteroscedasticity of error terms, a cluster option available in Stata for both probit and negative binomial regression estimations was employed, using the identification number of high schools as the clustering variable. The cluster option produces estimates of robust standard errors adjusted for within-group clustering. Standard errors produced in this way are typically larger than conventional standard errors, making it harder to reject the null hypothesis (Long \& Freese, 2006).

\footnotetext{
${ }^{2}$ Originally, race/ethnicity was used as an additional covariate but was later dropped due to collinearity with household income.

${ }^{3}$ Likelihood-ratio tests of alpha were performed to test for overdispersion for the count outcome variable. There was significant evidence of overdispersion for all estimated models $\left(\mathrm{G}^{2} \geq 2074.45, \mathrm{p}<.001\right)$.
} 


\section{Results}

\section{Descriptive Analyses}

Table 1 demonstrates that, out of 3,472 respondents, 13.5\% reported having experienced physical abuse, $4.2 \%$ sexual abuse, and $8.9 \%$ neglect before they started sixth grade. Bivariate contrasts using Chi-square tests and a t-test revealed that rates of maltreatment were not different between males and females: None of the five indicators of maltreatment revealed statistically significant differences between males and females. Yet, males reported having committed substantially more violent offenses than females in all of the three indicators of violent delinquency.

\section{[Insert Table 1 about Here]}

Bivariate correlation analyses (see Table 2) indicated that having experienced any maltreatment was positively and significantly related to violence, but analyses of maltreatment subtypes revealed a more complex pattern. To be specific, physical abuse was not associated with committing violent offenses. Sexual abuse was positively associated with violent offense participation, but statistical significance for sexual abuse disappeared when the continuous indicator of violence (frequency) was used. Neglect, however, was positively related with both participation and frequency indicators of violence. Also of interest were the findings pertaining to religiosity. Both public and private religiosity were negatively and significantly associated with violent delinquency participation; however, the magnitude of correlation was greater for private than public religiosity.

\section{[Table 2 about Here]}

\section{Multivariate Analyses}

Table 3 shows the results of fifteen multivariate models where three violent delinquency indicators are regressed on five different maltreatment subtypes separately, controlling for gender, household income, and private and public religiosity. For binary violent delinquent indicators, probit regressions with a cluster option were employed, while negative binomial regressions with a cluster option were used for continuous violent delinquent indicators. Predicted probabilities, their differences, and associated $p$-values for the regression coefficients for the maltreatment subtype of interest are presented. For the sake of brevity, values for covariates are omitted. Predicted probabilities for a maltreatment subtype were calculated holding all other covariates at their respective mean value.

\section{[Table 3 about Here]}

Looking at the top panel of Table 3, the zero-order correlations found in Table 2 seem to hold true at the multivariate level: Children with any maltreatment experience are significantly more likely to commit violent offenses in terms of both participation $(p=.002)$ and frequency $(p=.005)$; although, effect sizes are smaller than those found in previous studies ${ }^{4}$. The ES (Cohen's $d$ ) for participation was .11 and that for frequency was .10 .

When only exclusively violent offense participation is considered, the significant effect of maltreatment disappeared. The null effect of maltreatment on exclusively violent offending is consistently manifest for four other remaining maltreatment subtypes. This finding suggests that estimates from previous studies could have been inflated by not taking into account the fact that most adolescents engaging in violent offenses also engage in property offenses. It also might be that the positive association between maltreatment and violence found in the samples of disadvantaged at-risk children in previous studies is not as strong in a nationally representative sample ${ }^{5}$.

The statistically discernable effect of Any Maltreatment on the two delinquent indicators shown in the top panel begins to change when subtypes of maltreatment are analyzed separately. The second panel shows that regression coefficients for Physical Abuse are not statistically significant when predicting both participation and frequency

\footnotetext{
${ }_{5}^{4}$ For instance, most effect size estimates in Mersky \& Reynolds's (2007) study were between .4 and .6.

${ }^{5}$ Appendix A presents the results of five multivariate logistic regression models, where adolescents who committed violent offenses, who committed property offenses, and who committed both violent and property offenses were handled separately. In short, the results coincide with the probit regression results: None of the maltreatment indicators significantly predicted exclusively violent participation in comparison to nonoffenders.
} 
indicators of violence, controlling for demographic and religiosity covariates. Since the sample of this research is nationally-based and not focused on disadvantaged youth as most other locally-represented samples, the result of physical abuse on violence participation and/or frequency suggests that different mechanisms might underlie the nexus of maltreatment and violent delinquency among disadvantaged at-risk youths than among nationally representative samples of youths.

Both Sexual Abuse and Neglect, however, exhibit statistically discernable effects in predicting adolescents' participation in and frequency of violent engagements. It was somewhat surprising that sexual abuse and neglect, not physical abuse, predicted violence, given the previous findings that physical abuse is the most consistent type of abuse predicting future violence among youths (Maas et al, 2008).

The last panel shows the violence-inducing effects of substantiated maltreatment. Those who reported substantiated maltreatment constitute adolescents who were subject to the most serious forms of maltreatment during childhood in the sample and are probably equivalent to the disadvantaged adolescent youths examined in most previous studies. As expected, substantiated maltreatment predicted violence positively and significantly. To repeat, however, none of the maltreatment subtypes, including substantiated maltreatment, exhibited any significant effect on exclusive violence participation.

Before proceeding to investigate interactions between maltreatment and moderating variables, it is important to present the main effect estimation results in Table 4, using Any Maltreatment as the indicator of maltreatment. To take variance estimates into consideration, the ratio of regression coefficients to respective robust standard errors (Coef./Robust SE) are presented. Under the participation model, all predictors statistically meaningfully predict participation in violent delinquency in the expected manner, except for public religiosity. To provide a more intuitive feel, discrete changes associated with each predictor in the model are computed (see Long \& Feese, 2006). Discrete changes presented in Figure 1 reflect the change in the predicted probability of participating in violent delinquency when each independent variable changes its value from minimum to maximum, holding all other predictors at their respective mean value.

\section{[Table 4 about Here]}

As summarized in Table 4, experiencing any maltreatment increases the expected probability of committing violent delinquency by approximately $5 \%$ as opposed to experiencing no maltreatment. This effect, however, is small compared to the effects of most of the other predictors in the model. For instance, the difference in the probability was almost $35 \%$ between children from the lowest income households and children from the highest income households. Female respondents with a high private religiosity also had $15 \%$ lower probability of violent delinquency.

When the frequency of violent delinquency was estimated via negative binomial regression, the results bore a close resemblance to the results of the probit models which predicts participation in violence (see Table 4). When only exclusively violent delinquency was considered, however, maltreatment (nor private or public religiosity) did not predict delinquency. Only female and household income were negatively associated with exclusive violence participation ${ }^{6}$.

[Figure 1 about Here]

As alluded to earlier, the literature suggests that some of the direct effects from maltreatment to delinquency should be conditioned by certain moderators. To test this, interaction effects between Any Maltreatment and four moderators (female, household income, public religiosity, and private religiosity) were included in separate multivariate analyses. Specifically, a single interaction term between maltreatment and a moderator was added to a separate regression model. Despite the apparent main effects observed in Table 4, none of the interaction terms exhibited significance at the conventional .05 level (results not presented). Clearly the interaction hypotheses were not substantiated for the current model.

\footnotetext{
${ }^{6}$ Multinomial logit regression results in Appendix B demonstrate the same pattern.
} 


\section{Discussion}

Using a nationally representative sample of adolescents, the effects of child maltreatment on later engagement in violent delinquency were closely examined. In addition, moderating effects of gender, SES, and religiosity on the relationship between maltreatment and violent delinquency were tested. To navigate forward methodologically, careful study of the impacts of maltreatment on violence were conducted by differentiating the outcome variable into violence participation, violence frequency, and exclusive violence participation. In consonance with recent trend in maltreatment research, taxonomic categories that distinguished physical abuse, sexual abuse, and neglect were specified. Compared with earlier maltreatment studies that frequently relied on localized samples based on substantiated maltreatment or delinquency status, a large nationally representative sample of adolescents was used, thereby examining the effects of less serious maltreatment as well as enhancing the accuracy of statistical estimates.

Although this study's results generally support earlier findings, some of the results are noticeably unique. First and foremost, both zero-order correlations and multivariate analyses show that physical abuse, in itself, was not associated with future violent delinquency. This finding is in stark contrast with earlier studies that have consistently supported the cycle of violence thesis. The failure of this study to support the cycle of violence thesis does not seem to be an artifact of coding or other methodological technicalities; rather, it is suspected that the nature of this study's sample brought about this unexpected result. In other words, child maltreatment experienced by the nationally representative sample of children in this study is different from more extreme forms of child maltreatment that have been frequently studied by other researchers in the field of maltreatment. Previous studies frequently employed disadvantaged high-risk children samples or samples in which child maltreatment has been officially substantiated. It may be that less serious physical abuse experienced by a large portion of the sample has cancelled out the violence-inducing effect of more serious forms of physical abuse. We do acknowledge that it is an arbitrary decision to select three occasions of violence as the cut-off point for physical abuse. However, such an arbitrary decision offers consistency, at a minimum, in the ensuing analyses.

Secondly, none of the maltreatment indicators predict the outcome variable, exclusive violence participation. This outcome variable was designed to eliminate the confounding finding stemming from the fact that the majority of violent delinquents also commit property offenses. The null finding in this study suggests that previous studies did not mete out respondents who exclusively participated in violence compared to those who committed both violent and property offenses. This lack of methodological control may have overstated child maltreatment's violencegenerating effect. On the other hand, it might be that the null effect was primarily associated with the nature of the nationally representative sample. Future researchers might want to clarify this issue.

Although the current study did not uncover a significant association between physical abuse and violent delinquency, it would be myopic to deemphasize the deleterious effects of physical abuse. Rather, the results of this study are indicative of the difficulties in teasing out the association of physical abuse and violence, especially with regard to a nationally representative sample of adolescents. Even with the current sample, however, more serious forms of physical abuse, as partially reflected in substantiated maltreatment, were significantly associated with violent delinquency, controlling for gender, SES, and religiosity. Also unique to the current study, it was discovered that there is a strong association between sexual abuse and violence and between neglect and violence. In comparison to well-defined theoretical and empirical linkages between physical abuse and violence, there is a need to develop such connections with regard to neglect and sexual abuse. It should also be recognized that there exist multiple dimensions of neglect; the current study only examined two aspects of it - being left home alone and unmet basic needs. Future researchers are encouraged to employ more refined dimensions of neglect.

Few researchers have formally tested interaction effects in the context of child maltreatment and violent delinquency. With respect to the gap in this line of research, the current study is a contribution to the literature. Contrary to our expectations, however, no interaction effects were discovered in this study. It is argued that uncovering interaction effects could often be empirically elusive for several reasons (Aguinis, 2002; McClelland \& Judd, 1993). First, moderated regression studies with interaction terms typically produce wider confidence intervals and thus provide low statistical power, leading to an inflated Type II error rate (Aguinis, 2002; Goodhue, Lewis, \& Thompson, 2007; Mersky \& Reynolds, 2007). Second, tests of interactions are restrained by the magnitude of main effects (Aguinis, 2002; Goodhue et al., 2002); significant interactions are unlikely when strong main effects are partialled out. 
We would be remiss if we did not mention several limitations of this study. The Add Health study garners child maltreatment data from Wave III interviews when participants reached their early adulthood. Respondents at this stage were asked to report earlier maltreatment experiences by the time they started sixth grade retrospectively. Thus, unlike other methodologically robust prospective longitudinal studies that are specifically geared to examining the effect of child maltreatment, the Add Health data may suffer from recall errors and other biases related to retrospective data collection.

Except for central demographic covariates, the current study did not include any community-level predictors of maltreatment and delinquency. Although the current study accounted for potential inflation of standard errors due to within-group clustering, it did not directly investigate, for instance, the nested effects of poverty. Certain community-level variables may affect the likelihood of both maltreatment and delinquency. Furthermore, research is warranted to understand the nested effects of key variables on maltreated children through multilevel modeling studies.

We set the alpha at the conventional .05 level for all significant tests. Given the number of significant tests performed in Table 3, one might successfully argue that a more stringent alpha (e.g., .01) should have been used. Thus, caution should be exercised when interpreting the results. Finally, the Add Health study employs a cut-off point of sixth grade to collect maltreatment information, and the current study used Wave II data to collect information on delinquency. Respondents were, at a minimum, eighth graders during Wave II. Thus, the current study was able to preserve the time sequence of maltreatment and delinquency. Yet, the downside is that, by doing so, respondents who were maltreated after sixth grade were included in the reference group with non-maltreated children. In other words, this study failed to examine the effects of maltreatment occurring after sixth grade.

Future work overcoming these limitations may increase the understanding on the dynamics involving child maltreatment and delinquency. Identifying moderating effects of individual characteristics and uncovering the effects of community-level factors will also increase society's ability to craft prevention and intervention policies tailored to specific subgroups in greatest needs. At the minimum, comporting with previous findings, this study suggests that preventing maltreatment during childhood will help to reduce the occurrence of violent delinquency during adolescence. 


\section{References}

Aguinis, H. (2002). Estimation of interaction effects in organization studies. Organizational Research Methods, 5(3), 207-211.

Aiken, L., \& West, S. (1991). Multiple regression: Testing and interpreting interactions. Newbury Park, NJ: Sage Publications.

Amey, C., Albrecht, S., Miller, M. (1996). Racial differences in adolescent drug use: The impact of religion. Substance Use and Misuse, 31, 1311-1332.

Bearman, P., Jones, J., \& Udry, J. (1997). The National Longitudinal Study of Adolescent Health: Research design. Available at http://www.cpc.unc.edu/projects/addhealth/design

Byrk, A., \& Raudenbush, S. (1992). Hierarchical linear modeling. Newbury Park, Calif.: Sage.

Cicchetti, D., \& Barnett, D. (1991). Toward the development of a scientific nosology of child maltreatment. In D. Cicchetti \& W. Grove (Eds.), Thinking clearly about psychology: Essays in honor of Paul E. Meehl (pp. 346-377). Minneapolis: University of Minnesota Press.

Cicchetti, D., \& Toth, S. (1993). Child abuse: Child development, and social policy. Norwood, NJ: Ablex.

Cochran, J. \& Akers, R. (1989). Beyond hellfire: An exploration of the variable effects of religiosity on adolescent marijuana and alcohol use. Journal of Research in Crime and Delinquency, 26, 198-225.

Dodge, K., Pettit, G., \& Bates, J. (1997). How the experience of early physical abuse leads children to become chronically aggressive. In D. Cicchetti \& S. Toth (Eds.), Rochester Symposium on Developmental Psychopathology: Vol. 8. The effects of trauma on the developmental process (pp. 263-268). Rochester, NY: University of Rochester Press.

English, D. J. (1998). The extent and consequences of child maltreatment. The Future of Children, 8, 39-53.

English, D. J., Widom, C. S., \& Brandford, C. (2002). Childhood victimization and delinquency, adult criminality, and violent criminal behavior: A replication and extension (NCJRS 192291).

Farrington, D. (1989). Early predictors of adolescent aggression and adult violence. Journal of Family Violence, 20(5), 279-290. 
Goodhue, D., Lewis, W., \& Thompson, R. (2007). Research note-Statististical power in analyzing interaction effects: Questioning the advantage of PLS with product indicators. Information Systems Research, 18(2), 211-227.

Gourieroux, C., Monfort, A., \& Trognon, A. (1984). Pseudo maximum likelihood methods: Applications to Poisson models. Econometrica, 52, 701-720.

Herrenkohl, R., Egolf, B., \& Herrenkohl, E. (1997). Preschoold antecedents of adolescent assaultive behavior: A longitudinal study. American Journal of Orthopsychiatry, 67, 422-432.

Hirschi, T. (1969). Causes of delinquency. Berkeley, CA: University of California Press.

Johnson, B., De Li, S., Larson, D., \& McCullough, M. (2000). A systematic review of the religiosity and delinquency literature. Journal of Contemporary Criminal Justice, 16(1), 32-52.

Johnson, R., Marcos, A., \& Bahr, S. (1987). The role of peers in the complex etiology of adolescent drug use. Criminology, 25, 323-340.

Kim, J. (2008). The protective effects of religiosity on maladjustment among maltrated and nonmaltreated children. Child Abuse and Neglect, 32, 711-720.

Loeber, R., Pardini, D., Homish, D., Wei, E., Crawford, A., Farrington, D., et al. (2005). The prediction of violence and homicide in young men. Journal of Consulting and Clinical Psychology, 73, 1074-1088.

Long, S., \& Freese, J. (2006). Regression models for categorical dependent variables using Stata. College Station, TX: Stata Press.

Maas, C., Herrenkohl, T., \& Sousa, C. (2008). Review of research on child maltreatment and violence in youth. Trauma, Violence, and Abuse, 9(1), 56-67.

McClelland, G. H., \& Judd, C. M. (1993). Statistical difficulties of detecting interactions and moderator effects. Psychological Bulletin, 114, 376-390.

Mersky, J., \& Reynolds, A. (2007). Child maltrreatement and violent delinquency: Disentangling main effects and subgroup effects. Child Maltreatment, 12(3), 246-258.

Mertler, C. A. \& Vannatta, R. A. (2005). Advanced and multivariate statistical methods: Practical application and interpretation (3rd ed.). Los Angeles: Pyrczak. 
Miller, L., Davies, M., \& Greenwald, S. (2000). Religiosity and substance use and abuse among adolescents in the National Comorbidity Survey. Journal of the American Academy of Child and Adolescent Psychiatry, 39, 1190-1197.

Osgood, D. W. (2000). Poisson-based regression analysis of aggregate crime rates. Journal of Quantitative Criminology, 16, 21-43.

Regnerus, M. D., \& Elder, G. H., Jr. (2003). Staying on track in school: Religious influences in high- and low-risk settings. Journal for the Scientific Study of Religion, 42, 633-649.

Smith, C., \& Thornberry, T. P. (1995). The relationship between childhood maltreatment and adolescent involvement in delinquency. Criminology, 33, 451-479.

Snyder, H., \& Sickmund, M. (2006). Juvenile offenders and victims: 2006 national report. Washington, DC: U.S. Department of Justice, Office of Justice Programs, Office of Juvenile Justice and Delinquency Prevention.

Tittle, C., \& Welch, M. (1983). Religiosity and deviance: Toward a contingency theory of constraining effects. Social Forces, 61, 653-682.

U.S. Department of Health and Human Services. (2006). Child maltreatment 2004. Washington, DC: Government Printing Office.

Wallace Jr., J. M., \& Forman, T. A. (1998). Religion's role in Promoting health and reducing risk among American youth. Health Education \& Behavior, 25, 721-741.

Werner, E., \& Smith, R. (1982). Vulnerable but invincible: A longitudinal study of resilient children and youth. New York: McGraw-Hill.

Widom, C. S. (1989a). Child abuse, neglect, and violent criminal behavior. Criminology, 27, 251-271.

Widom, C. S. (1989b). Does violence beget violence? A critical examination of the literature. Psychological Bulletin, 106, 3-28.

Widom, C. S. (1989c). The cycle of violence. Science, 244, 160-166.

Widom, C., \& Maxfield, M. (2001). An update on the “cycle of violence.” Washington, DC: U.S. Department of Justice, Office of Justice Programs.

Zingraff, M., Leiter, J., Myers, K., \& Johnsen, M. (1993). Child maltreatment and youthful problem behavior. Criminology, 31(2), 173-202. 
This is an author-produced, peer-reviewed version of this article. The final, definitive version of this document can be found online at Journal of Interpersonal Violence, published by SAGE. Copyright restrictions may apply. DOI: 10.1177/0886260510362886

Zuravin, S. J. (1999). A review of definitions and measurement research. In H. Dubowitz (Ed.), Neglected children: Research, practice, and policy (pp. 261-277). Thousand Oaks, CA: Sage. 
Tables

Table 1: Descriptive Statistics for Maltreatment and Delinquency Indicators $(\mathrm{N}=3,472)$

\begin{tabular}{|c|c|c|c|c|}
\hline & \multirow[b]{2}{*}{ Total Sample } & \multicolumn{2}{|c|}{ Gender } & \multirow[b]{2}{*}{$X^{2}$} \\
\hline & & Male & Female & \\
\hline \multicolumn{5}{|l|}{ Maltreatment Indicators } \\
\hline Physical abuse (\%) & 13.54 & 14.06 & 13.09 & .70 \\
\hline Sexual abuse $(\%)$ & 4.15 & 3.75 & 4.49 & 1.18 \\
\hline Neglect $(\%)$ & 8.93 & 9.56 & 8.39 & 1.47 \\
\hline Aggregate maltreatment (\%) & 22.21 & 23.50 & 21.10 & 2.87 \\
\hline Substantiated maltreatment (\%) & 1.28 & 1.20 & 1.34 & .14 \\
\hline \multicolumn{5}{|l|}{ Delinquency Indicators } \\
\hline Violent offense participation (\%) & 29.32 & 37.00 & 22.76 & $1.18^{*}$ \\
\hline Violent offense frequency (mean) & .71 & 1.00 & .47 & $9.38 *$ \\
\hline Exclusive violent offense participation $(\%)$ & 14.03 & 17.00 & 11.49 & $21.76^{*}$ \\
\hline
\end{tabular}

$* \mathrm{p}<.05$
Note: For violent offense frequency, a $t$-value is presented instead of a chi-square value. 
This is an author-produced, peer-reviewed version of this article. The final, definitive version of this document can be found online at Journal of Interpersonal Violence, published by SAGE. Copyright restrictions may apply. DOI: 10.1177/0886260510362886

Table 2. Correlation Matrix

\begin{tabular}{|c|c|c|c|c|c|c|c|c|c|c|c|}
\hline & 1 & 2 & 3 & 4 & 5 & 6 & 7 & 8 & 9 & 10 & 11 \\
\hline 1. Violent offense participation & 1 & & & & & & & & & & \\
\hline 2. Violent offense frequency & $.650 *$ & 1 & & & & & & & & & \\
\hline $\begin{array}{l}\text { 3. Exclusively violent offense } \\
\text { participation }\end{array}$ & $.627 *$ & $.259 *$ & 1 & & & & & & & & \\
\hline 4. Physical abuse & .029 & .031 & .007 & 1 & & & & & & & \\
\hline 5. Sexual abuse & $.059 *$ & .019 & .024 & $.141 *$ & 1 & & & & & & \\
\hline 6. Neglect & $.064^{*}$ & $.058 *$ & .019 & $.159 *$ & $.041 *$ & 1 & & & & & \\
\hline 7. Any maltreatment & $.066^{*}$ & $.059 *$ & .019 & $.740 *$ & $.389 *$ & $.586^{*}$ & 1 & & & & \\
\hline 8. Female & $-.156^{*}$ & $-.157 *$ & $-.079 *$ & -.014 & .018 & -.020 & -.028 & 1 & & & \\
\hline 9. Household income & $-.074 *$ & $-.057 *$ & $-.069 *$ & -.021 & .022 & -.021 & -.008 & .003 & 1 & & \\
\hline 10. Public religiosity & $-.033^{*}$ & -.027 & $-.039 *$ & -.026 & -.000 & -.023 & -.031 & .026 & .029 & 1 & \\
\hline 11. Private religiosity & $-.056^{*}$ & $-.047 *$ & $-.045^{*}$ & $-.052 *$ & -.011 & -.025 & $-.054 *$ & $.085 *$ & .003 & $.808 *$ & 1 \\
\hline
\end{tabular}

$* \mathrm{p}<.05$ 
Table 3. Predicted Probabilities and Differences for Delinquency by Maltreatment Type

\begin{tabular}{|c|c|c|c|c|}
\hline \multirow[b]{2}{*}{ Delinquency Indicators } & \multicolumn{4}{|c|}{ Any Maltreatment } \\
\hline & Yes & No & Diff. & $\mathrm{P}$ \\
\hline Violence participation & .339 & .278 & .061 & .002 \\
\hline Violence frequencył & .774 & .614 & .160 & .005 \\
\hline \multirow[t]{3}{*}{ Exclusively violence participation } & .226 & .189 & .037 & .087 \\
\hline & \multicolumn{4}{|c|}{ Physical Abuse } \\
\hline & Yes & No & Diff. & $\mathrm{P}$ \\
\hline Violence participation & .312 & .288 & .025 & .290 \\
\hline Violence frequency† & .733 & .636 & .097 & .151 \\
\hline \multirow[t]{3}{*}{ Exclusively violence participation } & .223 & .193 & .003 & .241 \\
\hline & \multicolumn{4}{|c|}{ Sexual Abuse } \\
\hline & Yes & No & Diff. & $\mathrm{P}$ \\
\hline Violence participation & .442 & .285 & .157 & .000 \\
\hline Violence frequency† & .908 & .638 & .270 & .012 \\
\hline \multirow[t]{3}{*}{ Exclusively violence participation } & .275 & .193 & .092 & .086 \\
\hline & \multicolumn{4}{|c|}{ Neglect } \\
\hline & Yes & No & Diff. & $\mathrm{P}$ \\
\hline Violence participation & .387 & .282 & .105 & .002 \\
\hline Violence frequency $\dagger$ & .879 & .627 & .252 & .009 \\
\hline \multirow[t]{3}{*}{ Exclusively violence participation } & .242 & .192 & .05 & .143 \\
\hline & \multicolumn{4}{|c|}{ Substantiated Maltreatment } \\
\hline & Yes & No & Diff. & $\mathrm{P}$ \\
\hline Violence participation & .464 & .286 & .178 & .032 \\
\hline Violence frequency† & 1.362 & .628 & .734 & .012 \\
\hline Exclusively violence participation & .288 & .193 & .095 & .265 \\
\hline
\end{tabular}

$\dagger$ : Predicted values (adjusted means), rather than predicted probabilities, are estimated through negative binomial regression. Note: Gender, household income, and private and public religiosity are controlled for in all of the 15 regression models. 
This is an author-produced, peer-reviewed version of this article. The final, definitive version of this document can be found online at Journal of Interpersonal Violence, published by SAGE. Copyright restrictions may apply. DOI: 10.1177/0886260510362886

Table 4. Main Effects Models

\begin{tabular}{|c|c|c|c|c|c|c|}
\hline \multirow[b]{2}{*}{ Independent Variables } & \multicolumn{2}{|c|}{ Participation } & \multicolumn{2}{|c|}{ Frequency } & \multicolumn{2}{|c|}{ Exclusively Violence } \\
\hline & Coef./Robust SE & $\mathrm{P}$ & Coef./Robust SE & $\mathrm{P}$ & Coef./Robust SE & $\mathrm{P}$ \\
\hline Any maltreatment & 3.069 & .002 & 2.778 & .005 & 1.71 & .087 \\
\hline Female & -7.840 & .000 & -9.050 & .000 & -5.25 & .000 \\
\hline Household income & -2.880 & .004 & -2.412 & .016 & -4.89 & .000 \\
\hline Private religiosity & -2.676 & .007 & -2.302 & .021 & -1.81 & .070 \\
\hline Public religiosity & 1.211 & .226 & 1.309 & .191 & 0.16 & .867 \\
\hline
\end{tabular}




\section{Figure}

Figure 1. Discrete Changes in Predicted Probabilities of Participation in Violent Delinquency

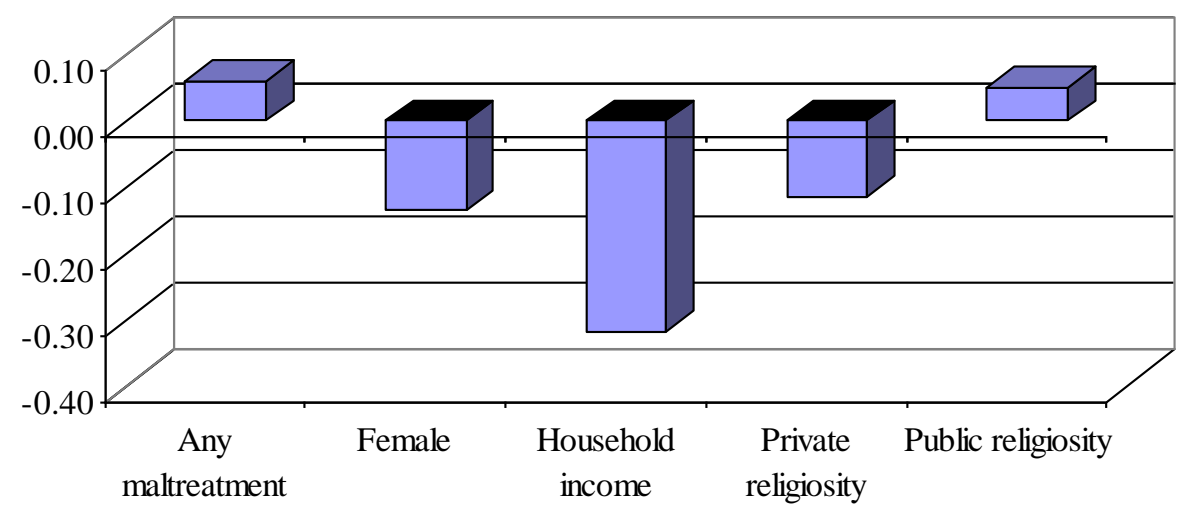




\section{Appendices}

Appendix A: Multinomial Logit Models for Violent and Property Delinquency Participation

\begin{tabular}{lccc}
\hline \multirow{2}{*}{ Maltreatment Indicator } & $\begin{array}{c}\text { Exclusively } \\
\text { violence offender }\end{array}$ & $\begin{array}{c}\text { Exclusively } \\
\text { property offender }\end{array}$ & Dual offender \\
\cline { 2 - 4 } & $\mathrm{b} 1$ & $\mathrm{~b} 2$ & $\mathrm{~b} 3$ \\
\hline Any maltreatment & $.19(.12)$ & $.26^{*}(.12)$ & $.47 * * *(.11)$ \\
Physical abuse & $.15(.15)$ & $.45^{* *}(.13)$ & $.31^{*}(.13)$ \\
Sexual abuse & $.46(.26)$ & $-.21(.03)$ & $.77 * *(.23)$ \\
Neglect & $.26(.19)$ & $.04(.18)$ & $.64 * * *(.18)$ \\
Substantiated maltreatment & $.49(.46)$ & $-1.01(.76)$ & $.67(.44)$ \\
\hline $\begin{array}{l}\text { Note: Multinomial logit coefficients and robust standard errors are reported. Gender, household income, } \\
\text { and private and public religiosity are controlled for in all of the five multinomial logistic regression } \\
\text { models. }\end{array}$. & \\
$* p \leq .05 * * p \leq .01 * * * p \leq .001$ &
\end{tabular}

Appendix B: Multinomial Logit Regression Main Effect Model

\begin{tabular}{lccc}
\hline \multirow{2}{*}{ Independent Variables } & $\begin{array}{c}\text { Exclusively } \\
\text { violence offender }\end{array}$ & $\begin{array}{c}\text { Exclusively } \\
\text { property offender }\end{array}$ & Dual offender \\
\cline { 2 - 4 } & $\mathrm{b} 1$ & $\mathrm{~b} 2$ & $\mathrm{~b} 3$ \\
\hline Any maltreatment & $.19(.12)$ & $.26^{*}(.12)$ & $.48^{* * *(.12)}$ \\
Female & $-.56^{* * *}(.11)$ & $-.21(.10)$ & $-.82^{* * *}(.11)$ \\
Household income & $-.01 * * *(.00)$ & $-.00(.00)$ & $-.01 *(.00)$ \\
Private religiosity & $-.13(.07)$ & $-.10 * .06)$ & $-.14 *(.06)$ \\
Public religiosity & $.01(.07)$ & $.05(.06)$ & $.11(.06)$ \\
\hline
\end{tabular}

Note: Multinomial logit coefficients and robust standard errors are reported.

$* p \leq .05 * * p \leq .01 * * * p \leq .001$

Appendix C: Multinomial Logit Regression Interaction Effect Model

\begin{tabular}{lccc}
\hline \multirow{2}{*}{ Interaction Term } & $\begin{array}{c}\text { Exclusively } \\
\text { violence offender }\end{array}$ & $\begin{array}{c}\text { Exclusively } \\
\text { property offender }\end{array}$ & Dual offender \\
\hline & $\mathrm{b} 1$ & $\mathrm{~b} 2$ & $\mathrm{~b} 3$ \\
\cline { 2 - 4 } Mal x Female & $.19(.26)$ & $-.19(.23)$ & $-.45(.26)$ \\
Mal x Household income & $.00(.00)$ & $.00(00)$ & $-.00(00)$ \\
Mal x Public religiosity & $.10(.09)$ & $.07(.08)$ & $.17(.09)$ \\
Mal x Private religiosity & $.06(.09)$ & $.08(.08)$ & $.15(.15)$ \\
\hline
\end{tabular}

Note: Multinomial logit coefficients and robust standard errors are reported. 